\title{
Incidence of chronic obstructive pulmonary disease in people with HIV in Ontario, 1996-2015: a retrospective population-based cohort study
}

\author{
Tony Antoniou PhD, Zhan Yao MSc, Janet Raboud PhD, Andrea S. Gershon MD MSc
}

Abstract

Background: Because of high smoking rates and HIV-related factors, people with HIV may be at high risk for chronic obstructive pulmonary disease (COPD); however, population-based estimates of the incidence of COPD among people with HIV are lacking, particularly for women. We compared the incidence of COPD among Ontario adults aged 35 years or more with and without HIV between Jan. 1, 1996, and Dec. 31, 2015.

Methods: We conducted a population-based study using Ontario's health administrative databases. We compared the incidence of COPD between people with and without HIV using standardized incidence ratios and generalized estimating equations with a log link function.

Results: We identified 1849 people with HIV and 1168727 HIV-negative people who were newly diagnosed with COPD between 1996 and 2015. People with HIV were younger than HIV-negative people (mean age 49.7 [standard deviation 10.4] yr v. 62.2 [standard deviation 14.8] yr; standardized difference 0.98). Rates of COPD were higher among people with HIV than among HIV-negative people (10.4 v. 9.0 cases per 1000 person-years; standardized incidence ratio $1.16,95 \%$ confidence interval [Cl] 1.10 to 1.21 ; adjusted rate ratio $1.34,95 \% \mathrm{Cl} 1.27$ to 1.41 ). In sex-stratified analyses, rates of COPD were higher among men with HIV (adjusted rate ratio $1.32,95 \% \mathrm{Cl} 1.24$ to 1.40 ) and women with HIV (adjusted rate ratio $1.54,95 \% \mathrm{Cl} 1.37$ to 1.72 ) than among men and women without HIV. In a sensitivity analysis, smoking explained observed differences in COPD incidence.

Interpretation: People with HIV had higher rates of incident COPD than HIV-negative people. This may reflect the disproportionately higher prevalence of smoking among the former.

\footnotetext{
mprovements in care have reduced HIV-related morbidity and mortality, such that noninfectious comorbid diseases now account for an increasing proportion of deaths among people with HIV. ${ }^{1-6}$ In the context of an aging population with rates of smoking and alcohol use that exceed those of the general population, ${ }^{7,8}$ studies characterizing the burden of comorbid disease in people with HIV are required to optimize their care.

Chronic obstructive pulmonary disease (COPD) is a debilitating illness that affects more than 380 million people worldwide and is projected to become the fourth-leading global cause of death by $20300^{9,10}$ A recent meta-analysis showed that the prevalence of COPD among people with HIV was greater than that among HIV-negative control populations (pooled odds ratio 1.14, 95\% confidence interval [CI] 1.05 to 1.25$) \cdot{ }^{11}$ Although smoking is the most well recognized risk factor for COPD, ${ }^{12}$ several studies have shown higher rates of COPD in people with HIV than in HIV-negative people after adjustment for smoking, which suggests that
}

immune and infectious factors may be involved in the pathogenesis of COPD in people with HIV. ${ }^{13-18}$ However, inferences from existing studies exploring the burden of COPD in people with HIV are limited by samples that were small and not population-based. ${ }^{13,14,19-21}$ In addition, studies characterizing the incidence of COPD in women with HIV are lacking, despite the increasing representation of women among global populations of people with $\mathrm{HIV} .^{22}$

Accordingly, we compared the incidence of COPD in people with and without HIV in Ontario, home to over $40 \%$ of Canadians with HIV. ${ }^{23}$ We hypothesized that, because of

Competing interests: None declared.

This article has been peer reviewed.

Correspondence to: Tony Antoniou, tantoniou @smh.ca CMAJ Open 2020. DOI:10.9778/cmajo.20190028 
HIV-related immune and inflammatory factors and a high prevalence of smoking, people with HIV would have a higher incidence of COPD than the general population.

\section{Methods}

\section{Setting}

We conducted a population-based study comparing the incidence of COPD among Ontario adults aged 35 years or more with and without HIV between Jan. 1, 1996, and Dec. 31, 2015. We selected this period because it corresponds with the advent of highly active antiretroviral therapy, the availability of modern, potent antiretrovirals and the ensuing reduction in HIV-related morbidity and mortality. We restricted our analyses to people more than age 35 because our COPD casefinding definition was validated in this population and COPD is less common in younger people, and to align with COPD surveillance reports. ${ }^{24}$

\section{Data sources}

We used Ontario's health administrative databases, which are linked securely by means of unique encoded identifiers and analyzed at ICES (www.ices.on.ca). We identified adults with HIV using the Ontario HIV Database, an administrative registry of Ontario residents with diagnosed HIV that was generated with a validated case-finding algorithm. ${ }^{25}$ We obtained hospital admission and emergency department data from the Canadian Institute for Health Information's Discharge Abstract Database and National Ambulatory Care Reporting System, respectively. We used the Ontario Health Insurance Plan database to identify claims for physician services, and obtained basic demographic and date of death data from the Registered Persons Database, a registry of all Ontario residents eligible for health insurance.

\section{Study population}

For each year of the study, we used the Registered Persons Database to identify all adults in Ontario aged 35 years or more who were alive and eligible for health insurance and did not have a diagnosis of COPD. From within this cohort, we identified people who had been diagnosed with HIV using the Ontario HIV Database. Human immunodeficiency virus status was a time-varying covariate, so that people could potentially contribute time to both the HIV-negative cohort and the HIV-positive cohort. People could enter the analysis in any year from 1996 to 2015 .

\section{Outcomes}

Our primary outcome was the incidence of COPD, and our exposure of primary interest was HIV infection. We calculated COPD incidence rates per 1000 person-years of observation for people aged 35 years or more as the collective number of newly diagnosed cases annually for the overall analysis period (1996-2015). Because COPD incidence did not increase linearly over time, we also treated year as a categoric variable by dividing our study period into 5 -year intervals (1996-2000, 2001-2005, 2006-2010, 2011-2015). We used an offset term to adjust for varying durations of follow-up during the calendar year period of interest. For people who died or lost health insurance eligibility during follow-up, we truncated their observation at the pertinent date.

We defined COPD using a previously validated case finding algorithm of 1 or more physician billing claims, or 1 or more hospital discharges, or both, with a diagnosis of COPD (International Classification of Diseases, 9th Revision codes 491, 492, 496; International Statistical Classification of Diseases and Related Health Problems, 10th Revision codes J41, J42, J43, J44). ${ }^{26}$ This case definition was found to have a sensitivity and specificity of $85.0 \%$ and $78.4 \%$, respectively, for identifying COPD with Ontario's health administrative records and has been used extensively to study outcomes among people with COPD..$^{27,28}$

\section{Statistical analysis}

We computed standardized differences to compare characteristics of people with and without HIV with a new diagnosis of COPD during the study period. Standardized differences of less than 0.1 indicate good balance between groups for a given covariate. $^{29}$

We calculated expected numbers of COPD cases in people with HIV by applying incidence rates from the HIV-negative population to the person-time accrued by people with HIV. We compared rates of COPD between people with and without HIV in 2 ways. First, we calculated standardized incidence ratios (SIRs) as the ratio of observed to expected number of COPD cases in people with HIV and derived $95 \%$ confidence intervals (CIs) around SIRs using an exact method. ${ }^{30} \mathrm{We}$ evaluated average annual percent changes in SIRs using joinpoint regression analysis (Joinpoint Regression Program, Version 4.0.4, Statistical Methodology and Applications Branch, Surveillance Research Program, National Cancer Institute). Next, we compared rates of incident COPD between people with HIV and a $1 \%$ random sample of people without HIV using generalized estimating equations Poisson regression analysis.

We adjusted models for fixed and time-varying covariates that could influence the risk of being diagnosed with COPD, including age, year (5-year intervals), sex, urban versus rural residence, socioeconomic status and comorbidity. Specifically, we included age and sex in our models to adjust for differences in the population structure between people with and without HIV. We adjusted for socioeconomic status and rural residence because people with HIV were disproportionately represented in low-income neighbourhoods and urban centres, and prior research has associated these variables with COPD. ${ }^{31}$ We adjusted for comorbidity burden to account for differences in the underlying health of people with and without HIV.

We determined patient socioeconomic status at the neighbourhood level using postal code information and Statistics Canada census data. We used the Charlson Comorbidity Index score to adjust for annual differences in comorbidity burden. We stratified analyses by sex to explore heterogeneity in the risk of COPD by HIV status among women and men. We used the quasi-likelihood under the independence model 
criterion to compare the fit of various models, with the smallest criterion value chosen as the best-fitting model. ${ }^{32} \mathrm{We}$ conducted all analyses using SAS version 9.3 (SAS Institute).

Because the health administrative databases do not include reliable information on smoking, we conducted a simple bias analysis to explore whether differences in rates of COPD could be explained by variations in smoking prevalence between people with and without HIV. ${ }^{33}$ Specifically, we explored the impact of smoking on adjusted relative rates using published estimates of the prevalence of smoking in Ontario residents with and without $\mathrm{HIV}^{34,35}$ and published estimates of the association between smoking and COPD ${ }^{12}$ (Appendix 1, available at www.cmajopen.ca/content/8/1/E83/ suppl/DC1).

\section{Ethics approval}

The use of data in this project was authorized under section 45 of Ontario's Personal Health Information Protection Act, which does not require review by a research ethics board.

\section{Results}

We identified 10480538 people aged 35 or more with a valid Ontario health card, of whom 1432584 died and 810819 lost health insurance eligibility during the study period. Among the remaining 8237135 people, we identified 1849 people with HIV and $1168727 \mathrm{HIV}$-negative people who were newly diagnosed with COPD between 1996 and 2015.

Compared to HIV-negative people, those with $\mathrm{HIV}$ were younger (mean age 49.7 [standard deviation 10.4] v. 62.2 [standard deviation 14.8]; standardized difference 0.98], and less likely to be female (18.6\% v. $49.2 \%$; standardized difference 0.68$)$ and rural residents (4.8\% v. $16.4 \%$; standardized difference 0.39) (Table 1). In addition, people with HIV had a greater comorbidity burden and were disproportionately represented in the lowest neighbourhood income quintile.

During the study period, we observed a higher incidence of COPD among people with HIV than among HIV-negative people (10.4 v. 9.0 cases per 1000 person-years; SIR 1.16, 95\% CI 1.10 to 1.21 ) (Table 2). Similar results were obtained on multivariable regression (adjusted rate ratio $1.34,95 \% \mathrm{CI}$ 1.27 to 1.41$)$.

The average annual percent change in the incidence of COPD did not change significantly over the study period among people with $\mathrm{HIV}(-1.5 \%$, 95\% CI $-5.8 \%$ to $2.9 \%)$, whereas it declined among $\mathrm{HIV}$-negative people $(-2.0 \%$, $95 \%$ CI $-2.6 \%$ to $-1.3 \%)$. Trends in SIRs for COPD showed an average annual percent increase of $1.2 \%$ (95\% CI $-0.1 \%$ to $2.4 \%$ ) (Figure 1 ). When examined according to 5 -year intervals, standardized incidence ratios were significantly higher for people with HIV than for HIV-negative people in 2006-2010 (SIR 1.35, 95\% CI 1.25 to 1.46 ) and 2011-2015 (SIR 1.16, 95\% CI 1.07 to 1.26 ) only (Table 2). However, on multivariable regression, people with $\mathrm{HIV}$ had higher rates of COPD than HIV-negative people in all 5 -year periods. We observed similar results when we stratified results by sex (Table 2).
Using a conservative estimate of a nearly fourfold increased risk of COPD among current smokers and a prevalence of smoking among Ontario residents with and without HIV of $32.7 \%$ and $11.3 \%$, respectively, we found that people with $\mathrm{HIV}$ were no longer at higher risk for COPD than HIV-negative people (adjusted rate ratio 0.92) (Appendix 1). Similar results were obtained for sex-stratified analyses using sexspecific estimates of the prevalence of smoking, with adjusted relative rates of COPD among men and women with HIV of 0.89 and 1.02 , respectively.

\section{Interpretation}

In our population-based study, we observed higher standardized and adjusted incidence rates of COPD among women and men with HIV than in HIV-negative people. Although a simple bias analysis showed that our results were sensitive to adjustment for smoking, this finding should be considered hypothesis generating given that we were unable to account for this variable directly using our databases.

Our findings build on those of other large studies examining the burden of COPD in people with HIV. Specifically, a study of 33420 people with $\mathrm{HIV}$ (98\% male) receiving care through the US Veterans Affairs Health Care System showed higher rates of COPD relative to $\mathrm{HIV}$-negative veterans less than (rate ratio $1.17,95 \%$ CI 1.11 to 1.24 ) and more than (rate ratio $1.08,95 \%$ CI 1.01 to 1.15 ) 50 years of age. ${ }^{21}$ Our study adds to these findings by being population-based in nature, thereby allowing us to study all people with HIV who were diagnosed with COPD over a 20 -year study period. We also found that people with HIV were diagnosed with COPD almost a decade younger than HIV-negative people. Furthermore, we found an increasing trend in the SIR, which may be explained by sustained higher rates of smoking in people with HIV relative to the general population and an increasing proportion of people with HIV aged 55 years or more $(7.4 \%$ in 2000 to $30.0 \%$ in 2015). ${ }^{36}$ Finally, we derived populationbased estimates of COPD in women with HIV.

Our study has important implications for the management of people with HIV. First, although population-level screening for COPD is currently not supported by evidence, a recently published guideline from the Global Initiative for Chronic Obstructive Lung Disease endorses spirometry for active case finding in patients with risk factors and symptoms. ${ }^{9}$ Because people with HIV may include a higher than average risk group of people at risk for COPD, screening spirometry may be appropriate for this population. Early diagnosis and intervention aimed at preventing loss of lung function may be particularly important for people with HIV and COPD, as several studies suggest that hospital admissions and emergency department use related to COPD are more common in this population relative to $\mathrm{HIV}$-negative people with COPD. ${ }^{37,38}$ Second, efforts to identify and implement smoking cessation strategies acceptable to people with HIV are required. Prior research has shown that smoking now accounts for more years of lost life among people with HIV who smoke than HIV infection itself. ${ }^{39}$ Yet comparatively few studies exist evaluating 


\begin{tabular}{|c|c|c|c|}
\hline \multirow[b]{2}{*}{ Characteristic } & \multicolumn{2}{|c|}{ No. $(\%)$ of people* } & \multirow[b]{2}{*}{$\begin{array}{c}\text { Standardized } \\
\text { difference }\end{array}$} \\
\hline & $\begin{array}{c}\text { HIV-positive } \\
n=1849\end{array}$ & $\begin{array}{l}\text { HIV-negative } \\
n=1168727\end{array}$ & \\
\hline $\begin{array}{l}\text { Age at COPD diagnosis, yr, } \\
\text { mean } \pm \text { SD }\end{array}$ & $49.7 \pm 10.4$ & $62.2 \pm 14.8$ & 0.98 \\
\hline $35-50$ & $1109(60.0)$ & $295145(25.2)$ & 0.75 \\
\hline $51-65$ & $581(31.4)$ & 372349 (31.9) & 0.01 \\
\hline $66-80$ & $138(7.5)$ & $354952(30.4)$ & 0.61 \\
\hline$>81$ & $21(1.1)$ & $146281(12.5)$ & 0.46 \\
\hline \multicolumn{4}{|l|}{ Sex } \\
\hline Female & $343(18.6)$ & $574911(49.2)$ & 0.68 \\
\hline Male & $1506(81.4)$ & $593816(50.8)$ & \\
\hline \multicolumn{4}{|l|}{ Neighbourhood income quintile } \\
\hline 5 (highest) & $226(12.2)$ & $194214(16.6)$ & 0.13 \\
\hline 4 & $232(12.5)$ & $211964(18.1)$ & 0.16 \\
\hline 3 & $276(14.9)$ & $229285(19.6)$ & 0.12 \\
\hline 2 & $395(21.4)$ & $255273(21.8)$ & 0.01 \\
\hline 1 (lowest) & $705(38.1)$ & $273384(23.4)$ & 0.32 \\
\hline Missing & $15(0.8)$ & $4607(0.4)$ & 0.05 \\
\hline Rural residence & $88(4.8)$ & $191541(16.4)$ & 0.39 \\
\hline \multicolumn{4}{|l|}{$\begin{array}{l}\text { No. of hospital admissions for } \\
\text { COPD in } 24 \text { mo after diagnosis }\end{array}$} \\
\hline Mean \pm SD & $1.8 \pm 1.8$ & $1.4 \pm 1.0$ & 0.24 \\
\hline Median (IQR) & $1(1-2)$ & $1(1-2)$ & 0.16 \\
\hline \multicolumn{4}{|l|}{$\begin{array}{l}\text { Charlson Comorbidity Index } \\
\text { score }\end{array}$} \\
\hline No hospital admissions & $779(42.1)$ & $583870(50.0)$ & 0.16 \\
\hline 0 & $376(20.3)$ & 351901 (30.1) & 0.23 \\
\hline 1 & $76(4.1)$ & $93203(8.0)$ & 0.16 \\
\hline$\geq 2$ & $618(33.4)$ & $139753(12.0)$ & 0.53 \\
\hline Diagnosis of asthma & $533(28.8)$ & 306935 (26.3) & 0.06 \\
\hline Died during follow-up & $512(27.7)$ & $392758(33.6)$ & 0.13 \\
\hline $\begin{array}{l}\text { Diagnosed with Pneumocystis } \\
\text { jirovecii pneumonia before } \\
\text { COPD diagnosis }\end{array}$ & $187(10.1)$ & NA & - \\
\hline $\begin{array}{l}\text { No. of years between HIV } \\
\text { diagnosis and COPD diagnosis, } \\
\text { mean } \pm \text { SD }\end{array}$ & $9.1 \pm 6.0$ & NA & - \\
\hline
\end{tabular}

strategies for smoking cessation in this population, and the success of interventions appears modest. ${ }^{40,41}$

\section{Limitations}

Our findings are strengthened by the population-based nature of our data, which allowed us to examine all Ontario residents with HIV who have entered care. However, our study has some limitations. We used administrative databases and did not have access to past or present smoking prevalence, information quantifying smoking history, duration and amount, marijuana use, injection drug use and laboratory data, including viral load and CD4 cell count. Similarly, we did not have reliable data on antiretroviral use. Although use of antiretroviral therapy has been associated with a lower risk of COPD in the 
Table 2: Standardized incidence ratios and adjusted rate ratios of chronic obstructive pulmonary disease

\begin{tabular}{|c|c|c|c|c|}
\hline \multirow[b]{2}{*}{ Group/period } & \multicolumn{2}{|c|}{ Rate per 1000 person-years $(95 \% \mathrm{Cl})$} & \multirow{2}{*}{$\begin{array}{c}\text { Standardized } \\
\text { incidence ratio } \\
(95 \% \mathrm{Cl})\end{array}$} & \multirow{2}{*}{$\begin{array}{c}\text { Adjusted rate ratio } \\
(95 \% \mathrm{Cl})^{\star}\end{array}$} \\
\hline & HIV & No HIV & & \\
\hline Overall & 10.4 (9.9 to 10.9$)$ & $9.0(9.0$ to 9.0$)$ & $1.16(1.10$ to 1.21$)$ & $1.34(1.27$ to 1.41$)$ \\
\hline $1996-2000$ & 11.3 (10.0 to 12.7$)$ & $10.7(10.7$ to 10.8$)$ & $1.06(0.94$ to 1.19$)$ & 1.25 (1.10 to 1.42$)$ \\
\hline $2001-2005$ & $9.1(8.2$ to 10.1$)$ & 8.5 (8.5 to 8.5$)$ & $1.07(0.96$ to 1.19$)$ & $1.23(1.10$ to 1.37$)$ \\
\hline 2006-2010 & 11.8 (10.9 to 12.8$)$ & 8.7 (8.7 to 8.8$)$ & $1.35(1.25$ to 1.46$)$ & $1.55(1.42$ to 1.70$)$ \\
\hline 2011-2015 & $9.8(9.0$ to 10.6$)$ & $8.4(8.4$ to 8.4$)$ & $1.16(1.07$ to 1.26$)$ & $1.26(1.16$ to 1.38$)$ \\
\hline \multicolumn{5}{|l|}{ Women } \\
\hline Overall & $12.1(10.9$ to 13.4$)$ & 8.5 (8.5 to 8.6$)$ & $1.42(1.27$ to 1.57$)$ & $1.54(1.37$ to 1.72$)$ \\
\hline $1996-2000$ & 17.5 (12.8 to 23.4$)$ & $10.1(10.1$ to 10.2$)$ & 1.73 (1.28 to 2.28$)$ & $1.80(1.34$ to 2.43$)$ \\
\hline $2001-2005$ & 12.2 (9.4 to 15.6$)$ & 8.2 (8.2 to 8.3$)$ & $1.48(1.15$ to 1.88$)$ & $1.48(1.15$ to 1.91$)$ \\
\hline $2006-2010$ & $13.0(10.6$ to 15.6$)$ & $8.3(8.3$ to 8.4$)$ & $1.56(1.29$ to 1.87$)$ & $1.64(1.35$ to 1.99$)$ \\
\hline $2011-2015$ & $10.3(8.6$ to 12.3$)$ & 7.8 (7.7 to 7.8$)$ & 1.33 (1.11 to 1.58$)$ & 1.41 (1.17 to 1.69$)$ \\
\hline \multicolumn{5}{|l|}{ Men } \\
\hline Overall & 10.1 (9.6 to 10.6) & 9.5 (9.5 to 9.5$)$ & 1.06 (1.01 to 1.12$)$ & $1.32(1.24$ to 1.40$)$ \\
\hline $1996-2000$ & 10.6 (9.2 to 12.0$)$ & 11.3 (11.3 to 11.4$)$ & $0.93(0.82$ to 1.06$)$ & $1.21(1.04$ to 1.40$)$ \\
\hline $2001-2005$ & 8.6 (7.7 to 9.7$)$ & 8.8 (8.8 to 8.9$)$ & 0.98 (0.87 to 1.10$)$ & 1.27 (1.11 to 1.45$)$ \\
\hline 2006-2010 & 11.5 (10.6 to 12.6$)$ & 9.2 (9.1 to 9.2 ) & $1.26(1.15$ to 1.38$)$ & $1.56(1.41$ to 1.73$)$ \\
\hline 2011-2015 & 9.6 (8.8 to 10.5$)$ & 9.1 (9.0 to 9.1$)$ & $1.06(0.97$ to 1.16$)$ & $1.20(1.08$ to 1.33$)$ \\
\hline
\end{tabular}

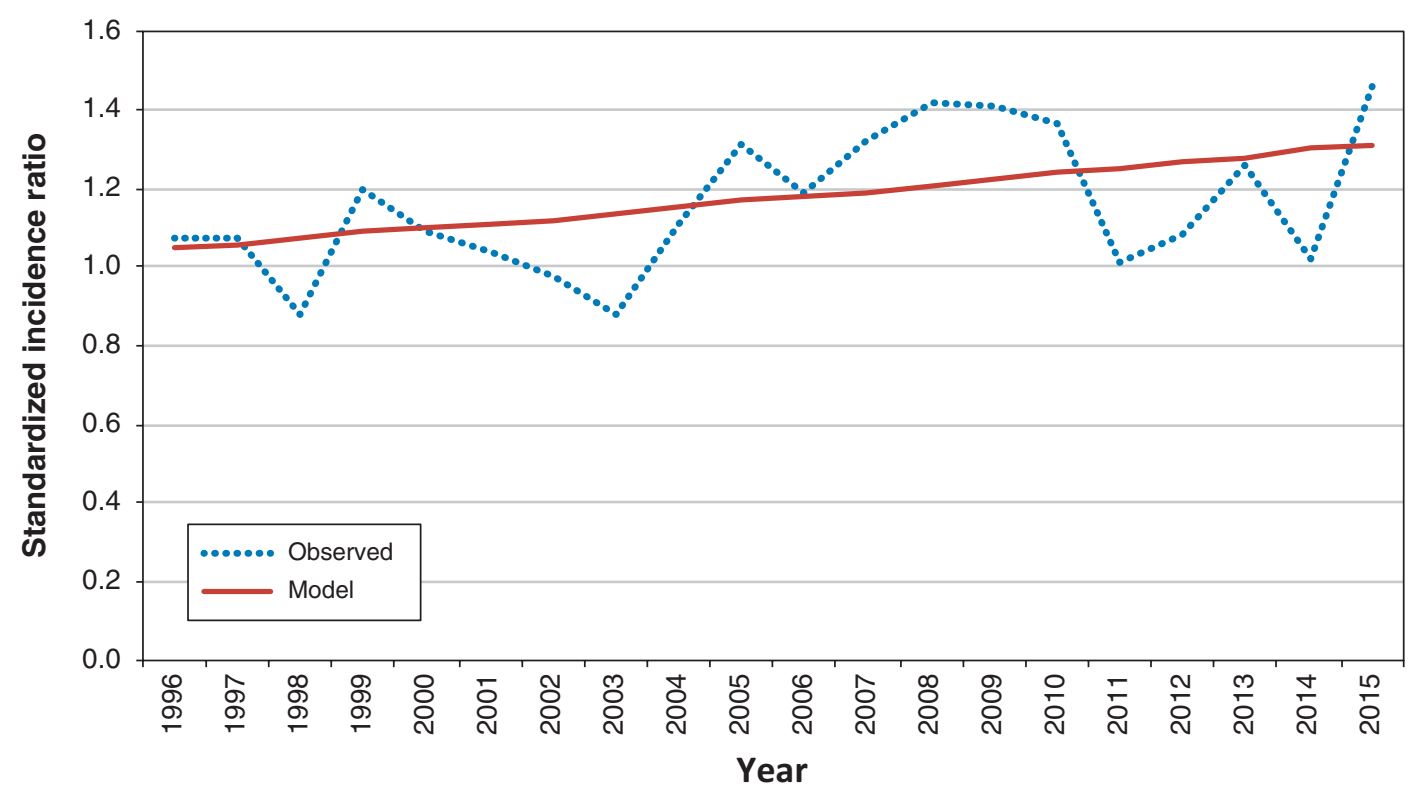

Figure 1: Trend in standardized incidence ratio of chronic obstructive pulmonary disease according to joinpoint regression model between people in Ontario with and without HIV, 1996-2015. 
Veterans Affairs study, ${ }^{21}$ other studies have found no differences in the rate of lung function decline according to HIV treatment status. ${ }^{42}$ Because most people with HIV who are in care in Ontario are receiving antiretroviral therapy, it is unlikely that low treatment uptake accounts for the increased risk of COPD in our cohort, particularly in later periods. ${ }^{43}$

We identified COPD using health administrative data rather than spirometry. Although it is possible that our validated case-finding algorithm identifies mostly people with clinically significant COPD and misses milder forms of the disease, thereby underestimating incidence, clinically significant disease would be more likely among people with HIV, in whom the prevalence of abnormal spirometry appears higher than in the general population. ${ }^{44,45}$ Finally, we could not identify people with undiagnosed HIV infection. Consequently, our estimates are most appropriately interpreted as representing the burden of COPD in people with diagnosed HIV infection who are in care.

\section{Conclusion}

We found higher than expected rates of COPD in people with HIV relative to $\mathrm{HIV}$-negative people. Our findings of a younger age at COPD diagnosis and higher rate among women with HIV relative to HIV-negative women are especially notable. Future areas of research include comparisons of the risk of spirometry-confirmed COPD in people with and without HIV and confirmation of our findings in large data sets that include missing confounders and HIV-related clinical information. In addition, research exploring the role of screening spirometry, the causal contribution of smoking and the longitudinal trajectory of COPD in people with HIV are required to better inform the clinical management of COPD in these patients.

\section{References}

1. Ingle SM, May MT, Gill MJ, et al.; Antiretroviral Therapy Cohort Collaboration. Impact of risk factors for specific causes of death in the first and subsequent years of antiretroviral therapy among $\mathrm{HIV}$-infected patients. Clin Infect Dis 2014;59:287-97.

2. Eyawo O, Franco-Villalobos C, Hull MW, et al.; Comparative Outcomes And Service Utilization Trends (COAST) study. Changes in mortality rates and causes of death in a population-based cohort of persons living with and without HIV from 1996 to 2012. BMC Infect Dis 2017;17:174.

3. Trickey A, May MT, Vehreschild J, et al.; Antiretroviral Therapy Cohort Collaboration (ART-CC). Cause-specific mortality in HIV-positive patients who survived ten years after starting antiretroviral therapy. PLoS One 2016;11: e0160460.

4. Deeks SG, Phillips AN. HIV infection, antiretroviral treatment, ageing, and non-AIDS related morbidity. BMF 2009;338:a3172.

5. Schouten J, Wit FW, Stolte IG, et al.; AGEhIV Cohort Study Group. Cross-sectional comparison of the prevalence of age-associated comorbidities and their risk factors between HIV-infected and uninfected individuals: the AGEhIV cohort study. Clin Infect Dis 2014;59:1787-97.

6. Guaraldi G, Orlando G, Zona S, et al. Premature age-related comorbidities among HIV-infected persons compared with the general population. Clin Infect Dis 2011;53:1120-6.

7. Crawford TN, Thornton AC. Alcohol use and multimorbidity among individuals living with HIV. AIDS Behav 2019;23:152-60.

8. Mdodo R, Frazier EL, Dube SR, et al. Cigarette smoking prevalence among adults with HIV compared with the general adult population in the United States: cross-sectional surveys. Ann Intern Med 2015;162:335-44.

9. Global strategy for the diagnosis, management, and prevention of chronic obstructive pulmonary disease: 2018 report. Fontana (WI): Global Initiative for Chronic Obstructive Lung Disease; 2018. Available: https://goldcopd.org/wp-content/ uploads/2017/11/GOLD-2018-v6.0-FINAL-revised-20-Nov_WMS.pdf (accessed 2018 Aug. 27).
10. Mathers CD, Loncar D. Projections of global mortality and burden of disease from 2002 to 2030. PLoS Med 2006;3:e442.

11. Bigna JJ, Kenne AM, Asangbeh SL, et al. Prevalence of chronic obstructive pulmonary disease in the global population with HIV: a systematic review and meta-analysis. Lancet Glob Health 2018;6:e193-202.

12. Eisner MD, Anthonisen N, Coultas D, et al.; Committee on Nonsmoking COPD, Environmental and Occupational Health Assembly. An official American Thoracic Society public policy statement: novel risk factors and the global burden of chronic obstructive pulmonary disease. Am 7 Respir Crit Care Med 2010;182:693-718.

13. Crothers K, Butt AA, Gibert CL, et al.; Veterans Aging Cohort 5 Project Team. Increased COPD among HIV-positive compared to HIV-negative veterans. Chest 2006;130:1326-33.

14. Nakamura H, Tateyama M, Tasato D, et al. The prevalence of airway obstruction among Japanese HIV-positive male patients compared with general population; a case-control study of single center analysis. F Infect Chemother 2014;20: 361-4.

15. Morris A, Kingsley LA, Groner G, et al. Prevalence and clinical predictors of Pneumocystis colonization among HIV-infected men. AIDS 2004;18:793-8.

16. Lozupone C, Cota-Gomez A, Palmer BE, et al.; Lung HIV Microbiome Project. Widespread colonization of the lung by Tropheryma whipplei in HIV infection. Am 7 Respir Crit Care Med 2013;187:1110-7.

17. Popescu I, Drummond MB, Gama L, et al. Activation-induced cell death drives profound lung CD4(+) T-cell depletion in HIV-associated chronic obstructive pulmonary disease. Am 7 Respir Crit Care Med 2014;190:744-55.

18. Twigg HL, Soliman DM, Day RB, et al. Lymphocytic alveolitis, bronchoalveolar lavage viral load, and outcome in human immunodeficiency virus infection. Am 7 Respir Crit Care Med 1999;159:1439-44.

19. Madeddu G, Fois AG, Calia GM, et al. Chronic obstructive pulmonary disease: An emerging comorbidity in HIV-infected patients in the HAART era? Infection 2013;41:347-53.

20. Risso K, Guillouet-de-Salvador F, Valerio L, et al. COPD in HIV-infected patients: CD4 cell count highly correlated. PLoS One 2017;12:e169359.

21. Crothers K, Huang L, Goulet JL, et al. HIV infection and risk for incident pulmonary diseases in the combination antiretroviral therapy era. Am 7 Respir Crit Care Med 2011;183:388-95.

22. UNAIDS data, 2018. Geneva: Joint United Nations Programme on HIV/ AIDS (UNAIDS); 2018. Available: www.unaids.org/sites/default/files/media_ asset/unaids-data-2018_en.pdf (accessed 2018 Aug. 27).

23. Public Health Agency of Canada. HIV and AIDS in Canada: surveillance report to December 31, 2014. Ottawa: Minister of Public Works and Government Services Canada; 2015. Available: www.canada.ca/en/public-health/services/publications/ diseases-conditions/hiv-aids-canada-surveillance-report-december-31-2014.html (accessed 2019 July 27).

24. Report from the Canadian Chronic Disease Surveillance System: asthma and chronic obstructive pulmonary disease (COPD) in Canada, 2018. Ottawa: Public Health Agency of Canada; 2018. Available: www.canada.ca/en/public-health/services/ publications/diseases-conditions/asthma-chronic-obstructive-pulmonary-disease -canada-2018.html (accessed 2019 July 24).

25. Antoniou T, Zagorski B, Loutfy MR, et al. Validation of case-finding algorithms derived from administrative data for identifying adults living with human immunodeficiency virus infection. PLoS One 2011;6:e21748.

26. Gershon AS, Wang C, Guan J, et al. Identifying individuals with physician diagnosed COPD in health administrative databases. COPD 2009;6:388-94.

27. Gershon A, Hwee J, Victor JC, et al. Mortality trends in women and men with COPD in Ontario, Canada, 1996-2012. Thorax 2015;70:121-6.

28. Gershon AS, Guan J, Victor JC, et al. Quantifying health services use for chronic obstructive pulmonary disease. Am 7 Respir Crit Care Med 2013;187:596-601.

29. Austin PC, Grootendorst P, Anderson GM. A comparison of the ability of different propensity score models to balance measured variables between treated and untreated subjects: a Monte Carlo study. Stat Med 2007;26:734-53.

30. Breslow NE, Day NE. Statistical methods in cancer research: volume II - the design and analysis of cohort studies. IARC Scientific Publications no. 82. Lyon (France): International Agency for Research on Cancer; 1987.

31. Raju S, Keet CA, Paulin LM, et al. Rural residence and poverty are independent risk factors for chronic obstructive pulmonary disease in the United States. Am 7 Respir Crit Care Med 2019;199:961-9.

32. Pan W. Akaike's information criterion in generalized estimating equations. Biometrics 2001;57:120-5.

33. Lash TL, Fox MP, Fink AK. Applying quantitative bias analysis to epidemiologic data. New York: Springer Science \& Business Media; 2011.

34. Bekele T, Rueda S, Gardner S, et al. Trends and correlates of cigarette smoking and its impacts on health-related quality of life among people living with HIV: findings from the Ontario HIV Treatment Network Cohort Study, 2008-2014. AIDS Patient Care STDS 2017;31:49-59.

35. Leos-Toro C, Reid JL, Madill CL, et al. Tobacco use in Canada: patterns and trends, 2017 edition. Waterloo (ON): Propel Centre for Population Health Impact, University of Waterloo; 2017.

36. Wilton J, Liu J, Sullivan A, et al.; Ontario HIV Epidemiology and Surveillance Initiative. Trends in HIV care cascade engagement among diagnosed people living with HIV in Ontario, Canada: a retrospective, population-based cohort study. PLoS One 2019;14:e210096. 
37. Depp TB, McGinnis KA, Kraemer K, et al. Risk factors associated with acute exacerbation of chronic obstructive pulmonary disease in HIV-infected and uninfected patients. AIDS 2016;30:455-63.

38. Ng R, Kendall CE, Burchell AN, et al. Emergency department use by people with HIV in Ontario: a population-based cohort study. CMAJ Open 2016;4: E240-8.

39. Reddy KP, Parker RA, Losina E, et al. Impact of cigarette smoking and smoking cessation on life expectancy among people with HIV: a US-based modeling study. 7 Infect Dis 2016;214:1672-81.

40. Ledgerwood DM, Yskes R. Smoking cessation for people living with HIV/ AIDS: a literature review and synthesis. Nicotine Tob Res 2016;18:2177-84.

41. Pool ER, Dogar O, Lindsay RP, et al. Interventions for tobacco use cessation in people living with HIV and AIDS. Cochrane Database Syst Rev 2016;(6): CD011120.

42. Kunisaki KM, Niewoehner DE, Collins G, et al.; INSIGHT START Pulmonary Substudy Group. Pulmonary effects of immediate versus deferred antiretroviral therapy in HIV-positive individuals: a nested substudy within the multicentre, international, randomised, controlled Strategic Timing of Antiretroviral Treatment (START) trial. Lancet Respir Med 2016;4:980-9.

43. Burchell AN, Gardner S, Light L, et al. Implementation and operational research: engagement in HIV care among persons enrolled in a clinical HIV cohort in Ontario, Canada, 2001-2011. F Acquir Immune Defic Syndr 2015;70:e10-9.

44. Drummond MB, Huang L, Diaz PT, et al. Factors associated with abnormal spirometry among HIV-infected individuals. AIDS 2015;29:1691-700.

45. Sampériz G, Guerrero D, López M, et al. Prevalence of and risk factors for pulmonary abnormalities in HIV-infected patients treated with antiretroviral therapy. HIV Med 2014;15:321-9.

Affiliations: ICES (Antoniou, Yao, Gershon); Department of Family and Community Medicine (Antoniou), Li Ka Shing Knowledge Institute, St. Michael's Hospital and University of Toronto; Toronto General Hospi- tal Research Institute (Raboud); Dalla Lana School of Public Health (Raboud), University of Toronto; Department of Medicine (Gershon), Sunnybrook Health Sciences Centre, Toronto, Ont.

Contributors: Andrea Gershon and Janet Raboud supervised the project. Tony Antoniou drafted the manuscript, and Zhan Yao, Janet Raboud and Andrea Gershon revised it critically for important intellectual content. All of the authors contributed to the study concept and design and data interpretation, approved the final version to be published and agreed to be accountable for all aspects of the work.

Funding: This study was funded by the Ontario HIV Treatment Network (grant JIDA 862) and ICES, which is funded by an annual grant from the Ontario Ministry of Health and Long-Term Care. Tony Antoniou is supported by a Clinician Investigator Award from the University of Toronto Department of Family and Community Medicine.

Disclaimer: This study was supported by ICES, which is funded by an annual grant from the Ontario Ministry of Health and Long-Term Care (MOHLTC). The sponsors had no role in the design or conduct of the study; in the collection, analysis or interpretation of the data; or in the preparation, review or approval of the manuscript. The opinions, results and conclusions reported in this article are those of the authors and are independent from the funding sources. No endorsement by ICES or the Ontario MOHLTC is intended or should be inferred.

Supplemental information: For reviewer comments and the original submission of this manuscript, please see www.cmajopen.ca/content/8/1/ E83/suppl/DC1. 